\title{
Attitudes Toward the Amish: Contact, Social Dominance, and Beliefs in Equality
}

\author{
Bryan D. Byers \\ Professor \\ Ball State University \\ bbyers@bsu.edu \\ William McGuigan \\ Professor Emeritus \\ Pennsylvania State University-Shenango \\ wmm11@psu.edu \\ James A. Jones \\ Director of Research and Academic Effectiveness \\ Ball State University \\ jjones@bsu.edu
}

\begin{abstract}
This study measured prejudice toward the Amish among the non-Amish using the Attitude Toward Amish scale. A sample of university students in the state of Indiana $(N=107)$ responded to an online survey instrument that was designed to replicate a previous study on what factors predict prejudice toward the Amish. The findings support some but not all of the predictors of anti-Amish prejudice found in the prior study. This study also measured knowledge of anti-Amish abusive behavior carried out by nonAmish. It was discovered that, as contact with the Amish increased, the odds of a respondent either hearing about or directly knowing of such conduct increased. The full findings are discussed, along with study strengths and weaknesses, potential application of the findings, and future research.
\end{abstract}

Submitted September 30, 2020; accepted April 2, 2021; published October 8, 2021

https://doi.org/10.18061/jpac.v2i1.7943

Keywords: prejudice, Amish, bias

$\mathrm{T}$ he purpose of this research is to replicate a study of prejudice against the Amish conducted by McGuigan and Scholl (2007), which was carried out in Pennsylvania. Pennsylvania is home to a large Old Order Amish settlement, the Lancaster Settlement. The present study was conducted in Indiana. Indiana also has some of the largest settlements in the United States, including the Elkhart-LaGrange and Nappanee settlements in the northern part of the state. Ohio also has a large group of Old Order Amish in the Holmes County Settlement. It is important to study prejudice toward the Amish since they are a fast-growing subculture and migrate to new areas around the United States in order to seek out economic opportunity. The Old Order Amish, under many circumstances, must interact with non-Amish to some degree. Interestingly, the Old Order Amish have been shown to care about "social relationships between Amish and outsiders," a finding that 
emerged as the fifth most common issue for Old Order Amish in a study of letters to the editor in the publication Family Life (Berg, 1997, p. 246).

Consistent with the original study by McGuigan and Scholl (2007), this replication tests the hypothesis that those with more contact with the Amish will have more favorable attitudes toward this subcultural group. An additional piece to this study, which was not addressed by McGuigan and Scholl, was to ask respondents if they have had any negative interactions with the Amish as described by Byers (2008), Byers and Crider (2002), and Byers et al. (1999) or if they were aware of any. Survey respondents in the current study were all university students who were current residents of Indiana, and the sample consisted of individuals who resided in counties with Amish citizens (we call these "Amish counties") and also individuals who resided in counties without Amish (we call these "non-Amish counties"), for purposes of comparison. There are 30 counties in Indiana with Amish residents, out of the total 92 counties. Thus, nearly 33\% of the counties within the state of Indiana have Old Order Amish residents. A sample method was utilized to attempt to draw a representative number of respondents from both types of counties (Amish and non-Amish) for purposes of comparison, based on knowledge of, and contact with, the Amish. However, the university student respondents sampled for this study only had an interest in participating if they were from an Amish county. Therefore, only student respondents from counties with Amish residents could be used for the analysis.

\section{The Old Order Amish}

The Old Order Amish are quite different in many ways from the dominant culture in American society. Difference, real or perceived, is a central foundation of prejudice. This group represents one type of Anabaptist faith group that emerged from the Protestant Reformation in Europe. The Amish have been extensively studied, and there is strong scholarship about the subculture (Hostetler, 1993, 1971, 1964, 1955; Hurst \& McConnell, 2010; Kraybill, 2001; Schreiber, 1962). There are a number of distinguishing qualities that symbolically separate the Amish as a subculture from the dominant culture marked by modernity. These qualities are steeped in strong tradition, custom, and oral history. Each of these defines who the Amish are as a group and reinforces Amish social identity within the individual as well as within a community. How the Amish define and give meaning to their social world is different than the dominant culture, while religio-social customs drive their lives much like they drive the lives of those in the dominant culture. In this section, we discuss two central tenets of the Old Order Amish subculture-Gelassenheit and Ordnung. The Amish embed these ways in their lives and social practices, and each has important meaning to them. In a word, the Amish do not typically engage in behavior that is not driven by religious-based Amish subcultural values, customs, and structure. Most everything they do is done for a reason linked to their faith, which is intertwined with their lifestyle and history and is marked by strong symbols of separation and submission.

In order to understand the Amish as a subcultural group and how Amish people interact with the outside world, one must grasp the concept of Gelassenheit. This is a German term that means to yield to a higher authority (Kraybill, 2001) and is the framework by which the Amish socially 
construct their realities. As Kraybill notes, "Various words in the Amish vocabulary capture the meaning of Gelassenheit: obedience, humility, self-denial, submission, thrift, and simplicity.... Gelassenheit is a master cultural disposition, deeply bred into the Amish soul, that governs perceptions, emotions, behavior, and architecture" (p. 29). Gelassenheit permeates every aspect of Amish life, from the most microscopic individual level to their macroscopic social organization, and it is how the Amish interact symbolically among themselves and with the non-Amish; it separates them as a subculture from the "outside" world in powerful ways.

Another important concept for understanding the Old Order Amish is Ordnung. This term basically refers to the system of rules that governs the Amish in settlement church districts. While there can be some variations from district to district, the basic foundations of Gelassenheit can be found in each Ordnung. The Ordnung is the unwritten but binding set of understandings that conveys the Amish subcultural expectations for conduct in all aspects of life-socially and spiritually. It is unwritten and is passed on via oral history to the group's younger members. Just as the non-Amish are taught social norms and mores in their socialization process, the Amish convey their norms and mores in the same manner. Learning one's Ordnung is a long process of integrating these institutionalized expectations for behavior into the Amish sense of self. Children reared in an Amish family should have a very clear understanding of these rules by the time they reach their teen years through continual teaching and social reinforcement. However, the lessons are often subtle and not overt. An Amish parent will not state, "Do not do that, as it is against the Ordnung." Rather, and similar to most of the lessons for non-Amish youth, the socialization takes place through the modeling of behavior by elders and the guidance provided to children during their lives. Each behavior or practice that is prescribed by the Ordnung reinforces the beliefs of submission, simplicity, and separation from the outside culture. Everything from social interaction, dress, and language to religious practices, marriage, and farming practices is socially defined by the Ordnung.

These unspoken rules are intended to create a peaceful, calm, and humble people whose ultimate authority is God. The Ordnung provides a predictable social ordering of the Amish way of life. It is, in a word, "social structure." There are times, however, when the Amish must adjust the Ordnung through a process of interpretation and reinterpretation as they negotiate with social change. This is most common when it comes to modernity. As Kraybill (2001) notes, the Amish must allow some degree of modernity given the powerful nature of the dominant culture. When the Amish are faced with a challenge to their way of life due to modernity, they define how, if necessary, the modernity will be allowed in the Ordnung.

\section{Literature}

Much research has been conducted on prejudice in American society. An important figure in the study of prejudice is Gordon Allport. His seminal work, The Nature of Prejudice (1954), addressed many aspects surrounding the concept of prejudice. Two important topics discussed by Allport are the Scale of Prejudice and the Contact Hypothesis. The Scale of Prejudice describes the levels of prejudice individuals can possess and convey to others. The Contact Hypothesis suggests that 
individuals with more positive interaction with those different than themselves will possess less prejudice toward members of another group. The Amish have experienced prejudice historically as well as in contemporary society and it is, therefore, important to discuss this group in relation to this particular dimension of social psychology.

A few authors have investigated the perceptions of the Amish by outsiders (McGuigan, 2014; McGuigan \& Scholl, 2007). To break down stereotypes and to promote positive social intercourse with others, Allport (1954) posited the Contact Hypothesis of interaction in race relations. The hypothesis maintains that attitudinal bias and social distance can be decreased through repeated in-group and out-group social contact and interaction (Allport, 1954; McGuigan \& Scholl, 2007). McGuigan and Scholl (2007) tested the Contact Hypothesis with the non-Amish using a variety of measures - including the Attitude Toward Amish (ATA) scale-with a final sample of 89 adult non-Amish respondents in an area with a $20 \%$ Amish population. The findings revealed that nonAmish adults who had more contact with Old Order Amish held less bias and more positive attitudes toward the Amish. In a more recent study, Anderson and Decker (2020) used the ATA to study both college student and non-college student attitudes in northeast Missouri. They discovered that the ATA instrument may suffer from problems with operational validity because the wording of some questions might reveal to respondents that the instrument measures prejudice. As a result, Anderson and Decker proposed a revised ATA (RATA) for use when measuring such attitudes. They also aptly point out that the measurement of prejudice is valuable because it can provide insights into behaviors.

The only authors to systematically study prejudice against the Amish and its behavioral consequences are Byers and Crider (2002), Byers et al. (1999), and Byers (2008). Byers et al. and Byers and Crider discovered from interviews that individuals who had harassed and intimidated the Old Order Amish in one Indiana county — which the non-Amish youth study subjects defined largely as "mischief"-held very strong negative opinions of the Amish that were steeped in stereotypes and misconceptions regarding Anabaptist culture and folkways. These social perceptions set the cognitive groundwork for the harsh treatment they meted out against unfortunate Old Order Amish victims. Interestingly, none of the subjects had any level of positive, ongoing interaction with their Old Order Amish neighbors even though they lived among them.

In these latter works, prejudice against the Amish is shown to influence harsh treatment toward this group, giving credence to the attitude-behavior link. These authors discovered during the course of anti-Amish hate crime research that prejudice toward the Amish was a common theme among the former bias crime offenders studied. The non-Amish former offenders possessed similar prejudiced and stereotypical attitudes and beliefs toward the Amish as a group as was found in other negative prejudicial intergroup relations.

\section{Method}

\section{Sampling}

Most Old Order Amish in Indiana reside in the Elkhart-LaGrange Settlement, which spans parts of three northcentral and northeastern counties in the state and borders the state of Michigan. The 
nearby, but distinct, Nappanee settlement spans parts of four counties: Elkhart, Kosciusko, Marshall, and a bit of Saint Joseph. Taken together, the Elkhart-LaGrange and Nappanee settlements span six counties, and Indiana has five of the 10 largest Amish settlements in the nation (Young Center for Anabaptist and Pietist Studies, 2020). There are also pockets of Old Order Amish in some 24 other counties in Indiana. In total, Indiana has over 45,000 Old Order Amish residents in 30 of its 92 counties, making it one of three states, along with Ohio and Pennsylvania, with the most Amish residents. Therefore, almost one-third of counties in the state of Indiana have Old Order Amish residents. For the purpose of this study, Indiana counties were categorized by their population of Old Order Amish residents as follows: less than 100; 100 to 999; 1,000 to 4,999; and 5,000 or more.

Participants, all non-Amish, were sampled from the student body of a medium-size public university within the state of Indiana. Students were sampled since it could be determined with relative ease if they came from Amish or non-Amish counties. This was initially important due to the desire to compare respondents from Amish versus non-Amish counties on the study scale items. Otherwise, it would have been much more difficult to reach potential respondents from all over the state representing the two types of counties because no frame for such sampling exists that includes email addresses for an online survey. The student sample included individuals from all over the state, with 3,674 enrolled from counties with more than 100 Amish residents ("Amish counties") and 12,751 enrolled from counties with fewer than 100 Amish residents ("non-Amish counties"). An initial sample of 1,000 was drawn from the population of students to identify 500 potential respondents from "Amish counties" (30 counties) and 500 from "non-Amish counties" (62 counties). An additional sample of 1,000 was drawn from counties with fewer than 100 Amish residents to increase the number of responses from participants from these counties, which was initially low. The final sample size based on responses was 132 . However, the final analysis included the 107 participants from the number who fully completed the instrument and who happened to come from Amish counties. Responses from subjects from non-Amish counties only came to 25, which was not enough for purposes of comparison and, thus, had to be excluded from this study. Therefore, the final sample of 107 respondents from Amish counties were used for this study and analysis.

\section{Instrument}

This study used an anonymous online questionnaire link provided to each individual sampled via their university email address. The questionnaire instrument consisted of three parts. First, basic demographic questions were asked, which included age, gender, county, hometown, year in school, and type of home residence (urban, suburban, rural). Second, respondents were asked to respond to four different scales. These were the Attitude Toward Amish (ATA) scale, the Contact Scale, the Belief in Equality (BE) Inventory, and the Social Dominance Orientation (SDO) scale. The ATA scale consists of 17 items adapted from MacConahay's (1986) racism scale to reflect prejudicial attitudes toward the Amish using a 5-point Likert scale. Validity and reliability ( $\alpha=$ .86) of the scale was established in previous studies (see McGuigan, 2014). Given when the data 
were collected, considerations regarding the RATA raised by Anderson and Decker (2020) could not be applied here. In addition to the ATA, questions were asked of respondents concerning any knowledge of, or participation in, acts of mistreatment toward the Old Order Amish. The following scales were also administered. Based on the Contact Hypothesis (Allport, 1954), a 20-item Contact Scale using a 3-point response range measured deep and superficial contact with the Amish (McGuigan \& Scholl, 2007; Pettigrew, 1998; $\alpha=.88$ ). The 10-item BE Inventory was used to measure the belief that there is an equal distribution of intelligence, ability, and potential across different social groups (Gray et al., 1994; $\alpha=.87$ ). The 10-item SDO scale was also administered. This measures beliefs that all societies are hierarchies based on nationality, ethnicity, and religion, and since groups are not equal, certain groups are inherently dominant over other groups (Pratto et al., 1994; Sidanius \& Pratto, 1999; $\alpha=.89)$. In addition to these scales, participants were asked to respond to a 17-item index measuring knowledge of the Amish (McGuigan \& Scholl, 2007; $\alpha$ $=.62$ ), which measures a respondent's knowledge of the characteristics and practices found within the Old Order Amish subculture. For instance, one question reads "Amish people ARE NOT very competitive among themselves." For this study, the internal consistency for all 17 items of the Amish knowledge scale was low $(\alpha=.44)$, so a subset of 7 items concerned with cultural knowledge ( $\alpha=.64)$ was used instead as a measure. The Need for Cognition Scale, an 18-item index measuring concrete versus abstract thought preferences (Cacioppo \& Petty, 1982; Cacioppo et al., 1984; Sadowski \& Gulgoz, 1992; $\alpha=.90$ ), was also used in this study. It was coded so that higher scores indicated preferences for more abstract thinking.

Specific questions were also asked concerning participants' knowledge of individuals engaging in abusive behavior toward the Old Order Amish. These questions were asked to determine to what extent the behavior found by previous researchers (Byers et al., 1999; Byers \& Crider, 2002) might be known by those in the present sample. Of these questions, two were fruitful in terms of the number of responses for purposes of analysis. These were "Have you ever heard of anyone who has harassed, intimidated, or teased an Amish person for fun/mischief?" and "Have you ever known a person (friend, acquaintance, schoolmate, etc.) who has harassed, intimidated, or teased an Amish person for fun/mischief?" The nature of these questions allowed the researchers to measure secondhand information about such behavior as well as direct knowledge.

\section{Findings}

The final sample included 107 respondents, with 26.2\% coming from counties with 5,000 or more Amish residents, $32.7 \%$ with 1,000 to $4,999,22.4 \%$ with 100 to 999 , and $18.7 \%$ from counties with fewer than 100 Amish residents. Descriptive statistics for the scales and sample characteristics can be found in Table 1. When comparing the impact of the Amish population within the county on the ATA, Contact Scale, BE, SDO, Amish Cultural Knowledge, and the Need for Cognition Scale using one-way analysis of variance (ANOVA), only the Contact Scale was found to show statistically significant differences $(F(3,103)=5.89, p=.001)$. Post hoc analyses showed that those in counties with 5,000 or more Amish residents had higher contact scores $(\bar{X}=$ 1.84) than those with 100 to $999(\bar{X}=1.44)$ or fewer than $100(\bar{X}=1.41)$ Amish residents. 
Table 1

Descriptive Statistics

\begin{tabular}{|c|c|c|c|}
\hline Variables & $N$ & Mean & $S D$ \\
\hline Attitude Toward Amish (ATA; high scores = positive) & 107 & 3.76 & .53 \\
\hline \multicolumn{4}{|l|}{ Amish county } \\
\hline$<100$ Amish residents & $20(18.7 \%)$ & & \\
\hline 100-999 Amish residents & $24(22.4 \%)$ & & \\
\hline 1,000-4,999 Amish residents & $35(32.7 \%)$ & & \\
\hline$\geq 5,000$ Amish residents & $28(26.2 \%)$ & & \\
\hline Amish Cultural Knowledge (higher scores $=$ more agreement) & 107 & 3.45 & .45 \\
\hline Contact (higher scores $=$ more contact) & 107 & 1.59 & .44 \\
\hline Concrete vs. abstract preference (higher scores $=$ more abstract) & 107 & 3.62 & .57 \\
\hline $\begin{array}{l}\text { Social Dominance Orientation (SDO; higher scores = more } \\
\text { dominance) }\end{array}$ & 107 & 1.75 & .62 \\
\hline Belief in Equity (BE; higher scores = more equity) & 107 & 4.00 & .58 \\
\hline $\begin{array}{l}\text { Please select the phrase that best describes where you are from } \\
(1=\text { urban, inside the city to } 5=\text { very much in the country })\end{array}$ & 107 & 3.62 & 1.26 \\
\hline What is your age? & 107 & 26.50 & 10.15 \\
\hline \multicolumn{4}{|l|}{ What is your gender? } \\
\hline Female (0) & $78(72.9 \%)$ & & \\
\hline Male (1) & $29(27.1 \%)$ & & \\
\hline \multicolumn{4}{|l|}{$\begin{array}{l}\text { Have you ever heard of anyone who has harassed, intimidated, } \\
\text { or teased an Amish person for fun/mischief? }\end{array}$} \\
\hline Yes (1) & $54(50.5 \%)$ & & \\
\hline No $(0)$ & $53(49.5 \%)$ & & \\
\hline \multicolumn{4}{|l|}{$\begin{array}{l}\text { Have you ever known a person (friend, acquaintance, } \\
\text { schoolmate, etc.) who has harassed, intimidated, or teased an } \\
\text { Amish person for fun/mischief? }\end{array}$} \\
\hline Yes (1) & $24(22.4 \%)$ & & \\
\hline No $(0)$ & $83(77.6 \%)$ & & \\
\hline
\end{tabular}

The potential predictors of the ATA were examined in an ordinary least squares (OLS) regression. The predictors included Amish Cultural Knowledge, Contact, abstract thinking, SDO, and BE scales plus age, gender, Amish population level in the county, and urban vs. rural location (e.g., "Where are you from?"). The resulting model produced an $R^{2}=.46(F(11,95)=7.34, p<$ $.001)$, indicating that $46 \%$ of the variability in the ATA could be accounted for by the model predictors. As shown by the coefficients in Table 2, having fewer than 100 versus 5,000 or more Amish residents, higher preference for abstract thinking, lower social dominance, and higher belief in equity all lead to higher predicted positive bias toward the Amish. 
Table 2

Coefficients for Predicting Attitude Toward Amish (ATA)

\begin{tabular}{|c|c|c|c|c|c|c|c|}
\hline \multirow[b]{2}{*}{ Predictors } & \multicolumn{2}{|c|}{$\begin{array}{l}\text { Unstandardized } \\
\text { Coefficients }\end{array}$} & \multirow{2}{*}{$\begin{array}{c}\text { Standardized } \\
\text { Coefficients } \\
\text { Beta }\end{array}$} & \multirow[b]{2}{*}{$t$} & \multirow[b]{2}{*}{$p$} & \multicolumn{2}{|c|}{$\begin{array}{c}\text { Collinearity } \\
\text { Statistics }\end{array}$} \\
\hline & $\mathrm{B}$ & $S E$ & & & & Tol & VIF \\
\hline \multicolumn{8}{|l|}{ Amish population } \\
\hline$<100$ vs. $100-999$ & -0.12 & 0.13 & -0.10 & -0.91 & .365 & .50 & 1.98 \\
\hline$<100$ vs. $1,000-4,999$ & -0.04 & 0.12 & -0.03 & -0.30 & .761 & .51 & 1.95 \\
\hline$<100$ vs. $\geq 5,000$ & -0.28 & 0.13 & -0.23 & -2.15 & .034 & .48 & 2.08 \\
\hline Amish Cultural Knowledge & 0.08 & 0.10 & 0.07 & 0.79 & .429 & .72 & 1.39 \\
\hline Contact & 0.18 & 0.11 & 0.15 & 1.67 & .099 & .69 & 1.45 \\
\hline Abstract thinking & 0.18 & 0.08 & 0.19 & 2.32 & .022 & .82 & 1.22 \\
\hline SDO & -0.18 & 0.08 & -0.21 & -2.19 & .031 & .61 & 1.63 \\
\hline BE & 0.31 & 0.09 & 0.34 & 3.42 & .001 & .58 & 1.73 \\
\hline Where you are from? & -0.06 & 0.04 & -0.15 & -1.73 & .087 & .79 & 1.27 \\
\hline What is your age? & 0.00 & 0.00 & 0.03 & 0.40 & .692 & .90 & 1.11 \\
\hline What is your gender? & -0.15 & 0.10 & -0.13 & -1.51 & .135 & .76 & 1.32 \\
\hline (Constant) & 1.96 & 0.54 & & 3.62 & $<.001$ & & \\
\hline
\end{tabular}

Note. Tol $=$ tolerance; VIF = Variance Inflation Factor.

$R^{2}=.46 ;$ Adj. $R^{2}=.40$.

A binary logistic regression was then used to examine which variables were associated with higher odds of hearing and knowing of someone who has harassed, intimidated, or teased an Amish person based on the research of Byers et al. (1999) and Byers and Crider (2002). The same predictors from the OLS regression plus the ATA were used as predictors. The model as a whole was statistically significant $\left(x^{2}=42.59, d f=12, p<.001\right)$, with a Nagelkerke $R^{2}=.44$. As shown in Table 3, each 1-point increase on the Contact Scale increased the predicted odds of hearing of someone harassing, intimidating, or teasing Amish persons by 38.84 times after controlling for all other predictors. Living in a county with a larger Amish population by itself was not a significant influence. 
Table 3

Have You Ever Heard of Anyone Who Has Harassed, Intimidated, or Teased an Amish Person for Fun/Mischief?

\begin{tabular}{lcccccccc}
\hline & & & & & & & \multicolumn{2}{c}{$95 \% \mathrm{Cl}$ for $e^{\mathrm{x}}$} \\
\cline { 6 - 9 } Predictors & $\mathrm{B}$ & $\mathrm{SE}$ & Wald & $d f$ & $p$ & $e^{\mathrm{x}}$ & $L L$ & $U L$ \\
\hline ATA & -0.66 & 0.72 & 0.85 & 1 & .357 & 0.52 & 0.13 & 2.11 \\
Amish Cultural Knowledge & -0.05 & 0.64 & 0.01 & 1 & .938 & 0.95 & 0.27 & 3.35 \\
Contact & 3.66 & 0.93 & 15.48 & 1 & $<.001$ & 38.84 & 6.27 & 240.50 \\
Amish population & & & 2.25 & 3 & .522 & & & \\
$\quad<100$ vs. 100-999 & -1.01 & 0.83 & 1.47 & 1 & .225 & 0.36 & 0.07 & 1.86 \\
$\quad<100$ vs. 1,000-4,999 & -0.58 & 0.72 & 0.64 & 1 & .423 & 0.56 & 0.14 & 2.30 \\
$\quad<100$ vs. $\geq 5,000$ & 0.01 & 0.84 & 0.00 & 1 & .987 & 1.01 & 0.19 & 5.31 \\
Abstract thinking & 0.23 & 0.47 & 0.24 & 1 & .626 & 1.26 & 0.50 & 3.13 \\
SDO & 0.14 & 0.57 & 0.06 & 1 & .812 & 1.15 & 0.37 & 3.52 \\
BE & 0.41 & 0.66 & 0.39 & 1 & .534 & 1.51 & 0.41 & 5.55 \\
Where you are from? & 0.00 & 0.22 & 0.00 & 1 & .986 & 1.00 & 0.64 & 1.54 \\
What is your age? & -0.04 & 0.03 & 3.09 & 1 & .079 & 0.96 & 0.91 & 1.01 \\
What is your gender? & -0.40 & 0.66 & 0.36 & 1 & .547 & 0.67 & 0.18 & 2.45 \\
Constant & -3.95 & 3.68 & 1.15 & 1 & .283 & 0.02 & & \\
\hline
\end{tabular}

Note. $\mathrm{Cl}=$ confidence interval; $L L=$ lower limit; $U L=$ upper limit.

Nagelkerke $R^{2}=.44$.

Moving from the question of hearing of someone to knowing someone who harassed, intimidated, or teased an Amish person, a second binary logistic regression was run with the new outcome variable but still using the same predictors as the first regression. The model as a whole was statistically significant $\left(x^{2}=40.71, d f=12, p<.001\right)$, with a Nagelkerke $R^{2}=.48$. As shown in Table 4 , the Contact Scale was still significant $(p=.001)$, but the ATA scale was now associated with a change in the odds. Each 1-point increase on the Contact Scale increased the predicted odds of knowing someone who harassed, intimidated, or teased an Amish person by 26.33 times after controlling for all other predictors, while each 1-point increase in the ATA resulted in an $88 \%$ decrease in the estimated odds. The BE scale also approached significance $(p=.078)$, with increases in BE resulting in higher predicted odds of knowing someone who harassed, intimidated, or teased an Amish person. However, one should be cautious concerning this association since the relationship was not statistically significant $(p<.10)$. Finally, there were not enough responses to the anonymous survey from people who self-reported that they had themselves mistreated the Amish to conduct any analyses. In retrospect, this makes sense since previous research on this topic used a focused qualitative snowball sampling technique to recruit participants, which assured that there would be subjects (Byers et al., 1999; Byers \& Crider, 2002). 


\section{Table 4}

Have You Ever Known a Person Who Has Harassed, Intimidated, or Teased an Amish Person for Fun/Mischief?

\begin{tabular}{lcccccccc}
\hline & & & & & & & \multicolumn{2}{c}{$95 \% \mathrm{Cl}$ for $e^{\mathrm{x}}$} \\
\cline { 6 - 9 } Predictors & $\mathrm{B}$ & SE & Wald & $d f$ & $p$ & $e^{\mathrm{x}}$ & $L L$ & $U L$ \\
\hline ATA & -2.09 & 0.86 & 5.96 & 1 & .015 & 0.12 & 0.02 & 0.66 \\
Amish Cultural Knowledge & -0.90 & 0.94 & 0.92 & 1 & .338 & 0.41 & 0.06 & 2.57 \\
Contact & 3.27 & 0.96 & 11.55 & 1 & .001 & 26.33 & 3.99 & 173.56 \\
Amish population & & & 1.55 & 3 & .670 & & & \\
$\quad<100$ vs. 100-999 & 1.55 & 1.50 & 1.07 & 1 & .301 & 4.72 & 0.25 & 89.39 \\
$\quad<100$ vs. 1,000-4,999 & 1.52 & 1.39 & 1.20 & 1 & .274 & 4.56 & 0.30 & 69.06 \\
$\quad<100$ vs. $\geq 5,000$ & 0.94 & 1.38 & 0.47 & 1 & .494 & 2.56 & 0.17 & 38.14 \\
Abstract thinking & 0.59 & 0.61 & 0.92 & 1 & .337 & 1.81 & 0.54 & 6.02 \\
SDO & 0.05 & 0.69 & 0.01 & 1 & .941 & 1.05 & 0.27 & 4.06 \\
BE & 1.45 & 0.82 & 3.10 & 1 & .078 & 4.25 & 0.85 & 21.29 \\
Where you are from? & 0.20 & 0.29 & 0.44 & 1 & .507 & 1.22 & 0.68 & 2.16 \\
What is your age? & -0.08 & 0.05 & 2.54 & 1 & .111 & 0.92 & 0.84 & 1.02 \\
What is your gender? & 0.36 & 0.75 & 0.23 & 1 & .635 & 1.43 & 0.33 & 6.26 \\
Constant & -4.12 & 5.06 & 0.66 & 1 & .416 & 0.02 & & \\
\hline
\end{tabular}

Note. $\mathrm{Cl}=$ confidence interval; $L L=$ lower limit; $U L=$ upper limit.

Nagelkerke $R^{2}=.48$.

\section{Discussion}

This research studied various dimensions of non-Amish individuals from Indiana counties with Amish populations concerning the reasons for their attitudes toward the Amish. An anonymous quantitative survey instrument was made available to participants, which included several scales along with the reliable and validated Attitude Toward Amish (ATA) scale (McGuigan, 2014). McGuigan and Scholl (2007) found that positive attitudes toward the Amish were associated with deep but not superficial contact between non-Amish and Amish. They also found that when the need for cognition was considered along with contact, these two factors explained about a quarter of the variance in attitudes among non-Amish toward Old Order Amish. The instrument used in this study also measured self-reported negative experiences and contact with the Amish. The reason for these questions stems from previous findings that suggested that some non-Amish youth can turn their attitudinal prejudice toward the Amish into behavior in the form of intimidation, harassment, and victimization (Byers et al., 1999; Byers \& Crider, 2002; Byers, 2008).

As expected, respondents coming from counties with larger Amish populations had higher contact scores. Respondents coming from counties with 5,000 or more Amish had the highest contact score on average, with those counties having 100 to 999 and then fewer than 100 following, in that order. However, the mean differences were not large. Even though the mean differences 
were small, the contact scores went in a predictable direction since larger Amish county populations would likely result in more contact.

The potential predictors of higher positive bias toward the Amish included coming from a county with fewer than 100 Amish residents, higher preference for abstract thinking, lower social dominance, and higher belief in equity. The aforementioned model explained $46 \%$ of the variability in the ATA. Conversely, Amish cultural knowledge, contact, age, gender, county Amish population level, and whether the respondent was from an urban or rural environment were not strong predictors of attitudes toward the Amish as measured by the ATA. The predictors of higher positive bias toward the Amish make sense other than population size. There is not much to be made of the significance of population since the contact scores were so close, on average, between the different-size Amish counties. However, there is something to be said about higher preference for abstract thinking, lower social dominance, and higher belief in equity, as each of these factors would logically predict higher positive bias toward the Amish.

To test the association among the variables in the model as well as the ATA on higher odds of hearing about someone harassing, intimidating, or teasing an Amish person, an OLS regression was run and shown to be statistically significant. In particular, each 1-point increase on the Contact Scale increased the predicted odds of hearing about these behaviors by 38.84 times after controlling for the other predictors. Interestingly, living in a county with a larger Amish population by itself was not a significant predictor. That higher contact scores were associated with selfreports of hearing about such instances seems logical. If a person has more contact with the Amish, they may be more likely to hear about such instances from the Amish themselves or from others they know who also have higher levels of contact.

In order to examine the relationship of knowing someone who harassed, intimidated, or teased an Amish person, the Contact Scale was also examined as a predictor. It was found that for each 1-point increase in the Contact Scale, the odds of knowing someone who engaged in this type of behavior against the Amish increased by 26.33 times after controlling for the other predictors. However, each 1-point increase in the ATA resulted in an $88 \%$ decrease in estimated odds. The $\mathrm{BE}$ scale approached significance with increases in BE resulting in higher predicted odds of knowing a person who harassed, intimidated, or teased an Amish person. Notwithstanding the other factors that influenced the odds of knowing of someone who engaged in such behavior, contact, again, was a strong predictor of having such knowledge. We would employ the same interpretation as before, which suggests that if a person has more contact with the Amish, they may be more likely to know about such instances from the Amish themselves or from others they know who also have higher levels of contact.

\section{Conclusion}

As discussed above, this study is a replication of the original study conducted by McGuigan \& Scholl (2007). In their study, it was shown that those with more contact with the Amish had more favorable attitudes toward the Amish. McGuigan and Scholl used a sample of individuals in the state of Pennsylvania. This study used a sample of individuals from Indiana. Both states have 
sizable Amish populations. In addition to using the same measures as McGuigan and Scholl, this study was expanded to also measure if respondents have heard about, or known of, a person who had harassed, intimidated, or teased an Amish person for fun or mischief. Respondents were also asked if they themselves had ever engaged in such conduct.

The findings from this study are valuable in shedding additional light on prejudice toward the Amish. Unlike previous research, this study did not find that more contact with the Amish elicits more positive attitudes toward the Amish. This is contrary to what was expected given prior research on prejudice against the Amish (McGuigan \& Scholl, 2007) as well as the Contact Hypothesis posited by Gordon Allport (1954). Thus, it appears the evidence is mixed in terms of levels of contact with the Amish having impact on attitudes toward them. However, there were variables other than contact that produced effects. For instance, more positive attitudes were associated with having larger numbers of Amish in counties when coupled with contact. Several other variables were also significant predictors of more positive attitudes toward the Amish. Higher preference for abstract thinking, more belief in equality, and lower social dominance orientation were all predictive of more positive bias toward the Amish. This was expected given the previous work of McGuigan and Scholl. However, levels of Amish cultural knowledge and the need for cognition were not sufficient predictors of prejudice against the Amish. Therefore, the findings of this study do not fully support those from previous research.

Hearing about Amish harassment/intimidation/teasing, however, was strongly predicted by contact. Each 1-point increase on the Contact Scale increased the predicted odds of hearing of someone harassing, intimidating, or teasing Amish persons by 38.84 times after controlling for all other predictors. Living in a county with a larger Amish population by itself was not a significant influence. Taking the notion of treatment toward the Amish a step further, this study also asked respondents if they had direct knowledge of anyone who harassed, intimidated, or teased an Amish person. As was the case concerning hearing about such behavior, contact was a strong predictor here as well. Each 1-point increase on the Contact Scale increased the predicted odds of knowing someone who harassed, intimidated, or teased an Amish person by 26.33 times after controlling for all other predictors. Conversely, each 1-point increase in the ATA resulted in an $88 \%$ decrease in the estimated odds of having such knowledge. While contact itself did not influence attitudes toward the Amish in this study, contact in the form of having a certain number of Amish in the same county as the respondents did predict more positive attitudes toward the Amish. While contact fell short in predicting positive bias toward the Amish, contact did strongly predict if a respondent had heard of poor treatment toward the Amish or knew of such incidents.

As with all studies, the present one has limitations. First, the sample used by McGuigan and Scholl (2007) was quite different than the sample in the current study. The current study used a sample of active college students at a medium-size midwestern university to better control sampling from counties with and without Amish populations. This was important to the researchers so attitudes and predictive variables could be compared across the different types of counties within the state. Unfortunately, there were not enough responses from individuals coming from "non-Amish counties" to make such comparisons. It is possible that those individuals have so little 
interest in the Amish that they do not want to participate in such studies or that they believe they have so little knowledge about the Amish that they are not comfortable participating. This, of course, also relates to the generally small final sample of respondents that could be used for analyses.

There are also strengths to the present study. First, there was a partial confirmation of the findings of McGuigan and Scholl (2007) in this replication. While not all of the predictive variables they used were found to be significant, a few were. For instance, higher preference for abstract thinking, more belief in equality, and lower social dominance orientation were all predictive of more positive bias toward the Amish. Conversely, levels of Amish cultural knowledge and the need for cognition were not sufficient predictors of prejudice against the Amish. Therefore, the findings of this study do not fully support those from previous research. Another strength is what was discovered in this study when examining the knowledge of people who had harassed, intimidated, or teased the Amish for fun, which was found in previous research (Byers et al., 1999; Byers \& Crider, 2002; Byers, 2008). First, the reports of such behavior in the present study, as revealed by some respondents, confirms its existence quantitatively when the original studies were qualitative. Therefore, the problem of anti-Amish behavior is real, although we may never know its true frequency due to Amish apprehensions concerning reporting such victimization (Byers et al., 1999; Byers \& Crider, 2002). What is also interesting, and a second strength, was the finding that levels of contact with the Amish was a predictor of hearing about such conduct and personally knowing of individuals who had engaged in such conduct. Intuitively, this makes sense since there would presumably be more opportunities to hear about poor treatment of the Amish within Amish counties in Indiana.

There are several implications of these findings. As a replication of a previous study, the present study showed that only some of the findings from the original work could be supported. This is valuable as future researchers go forward with studies on anti-Amish prejudice. Using the predictors in the original study by McGuigan and Scholl (2007) that were supported in the present study, one could apply the findings in communities where Amish and non-Amish reside to better understand the dynamics of intergroup relations, at least from the non-Amish perspective. One of the more important findings here is the influence of contact on hearing about or having knowledge of non-Amish engaging in abusive behavior toward the Amish. There are a few points to be made here. It is valuable, first, that it was discovered that some respondents had heard about or had direct knowledge of such conduct. This supports previous research by Byers et al. (1999) and Byers and Crider (2002). What is particularly interesting is the strong association between contact and responses to these items. As contact increased, the odds of having such knowledge either indirectly or directly also increased. This is valuable because more research might be conducted to delve deeper into such knowledge among non-Amish who live among the Amish. Specific community or settlement-based studies would seem fruitful should future researchers wish to explore this further. 


\section{References}

Allport, G. W. (1954). The nature of prejudice. Addison-Wesley.

Anderson, C., \& Decker, L. (2020). Evaluation and revision of an instrument measuring attitudes toward the Amish. Journal of Applied Social Science, 14(2), 195-211. https://doi.org/10.1177/1936724420947339

Berg, P. (1997). The plain people speak their minds: Amish letters to the editor. Sociological Imagination, 34(4), 244-252.

Byers, B. (2008). Amish victimization and offending: A rural subculture experiences and responses to crime and justice. Southern Rural Sociology, 23(2), 226-251.

Byers, B., \& Crider, B. (2002). Hate crimes against the Amish: A qualitative analysis of bias motivation using routine activities theory. Deviant Behavior, 23(2), 115-148. https://doi.org/10.1080/016396202753424529

Byers, B., Crider, B., \& Biggers, G. (1999). Bias crime motivation: A study of hate crime and offender neutralization techniques used against the Amish. Journal of Contemporary Criminal Justice, 15(1), 78-96. https://doi.org/10.1177/1043986299015001006

Cacioppo, J. T., \& Petty, R. E. (1982). The need for cognition. Journal of Personality and Social Psychology, 42(1), 116-131. https://doi.org/10.1037/0022-3514.42.1.116

Cacioppo, J. T., Petty, R. E., \& Kao, C. F. (1984). The efficient assessment of need for cognition. Journal of Personality Assessment, 48(3), 306-307. https://doi.org/10.1207/s15327752jpa4803 13

Gray, D. B., Connor, S., \& Decatur, M. (1994). The Belief in Equality Inventory and leadership behavior: A construct validation. Journal of Applied Social Psychology, 24(4), 367-377. https://doi.org/10.1111/j.1559-1816.1994.tb00587.x

Hostetler, J. A. (1955). Old world extinction and new world survival of the Amish: A study of group maintenance and dissolution. Rural Sociology, 20, 212-219.

Hostetler, J. A. (1964). Persistence and change patterns in Amish society. Ethnology, 3(2), 185198. https://doi.org/10.2307/3772711

Hostetler, J. A. (1971). Children in Amish society: Socialization and community education. Holt, Rinehart and Winston.

Hostetler, J. A. (1993). Amish society (4th ed.). Johns Hopkins University Press.

Hurst, C. E., \& McConnell, D. L. (2010). An Amish paradox: Diversity and change in the world's largest Amish community. Johns Hopkins University Press.

Kraybill, D. B. (2001). The riddle of Amish culture (Rev. ed.). Johns Hopkins University Press.

MacConahay, J. B. (1986). Modern racism, ambivalence, and the Modern Racism Scale. In J. F. Dovidio \& S. L. Gaertner (Eds.), Prejudice, discrimination, and racism (pp. 104-108). Academic Press.

McGuigan, W. (2014). Reliability and validity of a scale to measure prejudice toward Old Order Amish. Journal of Amish and Plain Anabaptist Studies, 2(1), 147-154.

https://doi.org/10.18061/1811/59684 
McGuigan, W., \& Scholl, C. (2007). The effect of contact on attitudes toward Old Order Amish. Journal of Applied Social Psychology, 37(11), 2642-2659. https://doi.org/10.1111/j.1559$\underline{1816.2007 .00274 . \mathrm{x}}$

Pettigrew, T. (1998). Intergroup contact theory. Annual Review of Psychology, 49(1), 65-85. https://doi.org/10.1146/annurev.psych.49.1.65

Pratto, F., Sidanius, J., Stallworth, L. M., \& Malle, B. F. (1994). Social dominance orientation: A personality variable predicting social and political attitudes. Journal of Personality and Social Psychology, 67(4), 741-763. https://doi.org/10.1037/0022-3514.67.4.741

Sadowski, C. J., \& Gulgoz, S. (1992). Internal consistency and test-retest reliability of the Need for Cognition Scale. Perceptual and Motor Skills, 74(2), 610. https://doi.org/10.2466/pms.1992.74.2.610

Schreiber, W. I. (1962). Our Amish neighbors. University of Chicago Press.

Sidanius, J., \& Pratto, F. (1999). Social dominance: An intergroup theory of social hierarchy and oppression. Cambridge University Press. https://doi.org/10.1017/CBO9781139175043

Young Center for Anabaptist and Pietist Studies. (2020). Twelve largest settlements, 2020. Amish Studies. http://groups.etown.edu/amishstudies/statistics/twelve-largest-settlements$\underline{2020 /}$

\section{Erratum}

10/11/2021: DOI link for article corrected. 